\title{
Simulation is more than working with a mannequin: Student's perceptions of their learning experience in a clinical simulation environment
}

\author{
Karla G. Rodriguez *, Noreen Nelson, Mattia Gilmartin, Lloyd Goldsamt, Hila Richardson \\ College of Nursing, NYU Meyers College of Nursing, New York, United States
}

Received: September 14, 2016

DOI: $10.5430 /$ jnep.v7n7p30

\author{
Accepted: January 6, 2017 \\ Online Published: February 14, 2017 \\ URL: http://dx.doi.org/10.5430/jnep.v7n7p30
}

\begin{abstract}
Purpose: This paper describes undergraduate nursing students' assessment of learning in a clinical teaching model that replaces $50 \%$ of the traditional clinical hours with high-fidelity simulation. We assessed students' perceptions of the use of best practices in simulation teaching, and the importance assigned to each teaching practice to support learning.

Methods: Longitudinal program evaluation design. We surveyed undergraduate nursing students with the Educational Practices Questionnaire (EPQ) at the mid-point (semester 2) and end of the program (semester 4). We used paired $t$-tests to assess changes in student EPQ scores between mid- and end-program.

Results: Results showed that students' reported greater exposure over time to clinical simulation activities that fostered active learning and high expectations; the degree to which they rated collaborative learning as important also increased.

Conclusions: Students' perceptions of the use of educational best practices and the importance of simulation in nursing education from program mid-point to end-point lends support for a clinical teaching model that uses a simulation to substitute for traditional clinical hours.
\end{abstract}

Key Words: Nursing students, High-fidelity simulation, Educational best practices

\section{INTRODUCTION}

To meet the challenge of preparing a new generation of competent practitioners, nurse educators have adopted teaching approaches that favor learning-by-doing and reflective practice. ${ }^{[1]}$ One of the active learning methods used in nursing education is high-fidelity simulation. ${ }^{[2]}$ Although simulation has been used to teach basic nursing skills for most of the twentieth century, contemporary simulation approaches give students experience working through complex clinical scenarios in a safe learning environment. ${ }^{[2,3]}$ High-fidelity simulation in nursing education involves teaching approaches such as task-trainers used to develop psycho-motor skills; standardized patients using actors; games and virtual reality platforms; and computerized mannequins that replicate the human anatomy that can be programmed to imitate a realistic physiologic response in a scripted situation. ${ }^{[4,5]}$

One advantage of high-fidelity simulation over traditional clinical teaching approaches is the ability to create a realistic controlled learning environment that maximizes the potential for student learning while minimizing potential harm to patients. Based on problem-based learning theories, high fidelity simulation scenarios provide students with the opporStates. 
tunity to work through progressively more complex scenarios to develop clinical reasoning and reflective practice skills. ${ }^{[5]}$ The American Association of Colleges of Nursing reports that there has been a large increase in the use of high-fidelity simulation in higher nursing education ${ }^{[6]}$ and the National Council of State Boards of Nursing endorses the use of welldesigned high-fidelity clinical simulation approaches as an appropriate method to develop the clinical competencies of new nurses. ${ }^{[7]}$

Although high-fidelity simulation using human mannequin simulators can facilitate problem-based learning among undergraduate nursing students, less attention has been paid to student perceptions of the quality and usefulness of simulation within the context of undergraduate education. ${ }^{[4,8-11]}$ Drawing from a larger program evaluation study, we present data on student perceptions of their clinical training in an undergraduate nursing program in which $50 \%$ of total clinical contact hours in each of the four nursing core medicalsurgical courses are taught using high-fidelity human mannequin simulation.

\subsection{Literature review}

\subsubsection{Simulation}

High fidelity simulation using human mannequin simulators is a common form of problem-based learning used in higher nursing education. ${ }^{[3]}$ Problem-based learning in undergraduate nursing education cultivates clinical reasoning and effective problem solving skills that are fundamental for expert clinical practice. ${ }^{[3,6-8,12]}$ Teaching congruent with the principles of problem based learning provides students with the necessary structure, guidance, and skills to grapple with clinically-relevant patient problems. Problem-based learning is especially effective for solving problems with more than one possible course of action, a situation that is common in clinical nursing practice.

Unlike traditional lecture teaching formats where students are passive participants, problem-based learning requires that students play an active role in mastering course content through a process of self-reflection, teamwork, communication and performance feedback. ${ }^{[1,8]}$

Instructors serve as guides and coaches who facilitate students' learning by framing problems, highlighting concepts and principles for problem solving, and support the process of independent learning. ${ }^{[1,2]}$ To the extent that faculty follow best practices to structure and manage student's independent learning, student performance and satisfaction with learning are enhanced. ${ }^{[13-16]}$

A growing body of evidence suggests that problem-based teaching methods promote students' critical thinking abili-

Published by Sciedu Press ties, knowledge retention, self-confidence and communication. ${ }^{[8,14]}$ A student's level of confidence during simulation can greatly affect and sharpen critical thinking abilities, technical competence, and overall quality of nursing care. ${ }^{[3,5]}$ Studies examining the relationship between self-confidence and high-fidelity simulation show that high fidelity simulation increases self-confidence with clinical practice abilities for the majority of students. ${ }^{[17-21]}$

Because of the realism of high-fidelity human simulators, this form of clinical simulation can be viewed as equally valuable to learning experiences gained from traditional, hospitalbased clinical teaching. ${ }^{[18-22]}$ Although substituting high fidelity simulation for traditional hospital-based clinical teaching holds much potential for modernizing nursing education, it is not without controversy. ${ }^{[3]}$ To assess the effectiveness of high fidelity simulation in developing students' clinical proficiency, the National Council of State Boards of Nursing sponsored a national randomized control trial comparing student outcomes across three clinical teaching models with varying levels of high fidelity human mannequin simulation. The trial results showed no significant difference in licensing exam scores (NCLEX-RN) among participating students assigned to a simulation teaching model in which $50 \%$ of the clinical hours were spent in high-fidelity simulation sessions using human mannequin simulators as compared to students educated in the traditional hospital-based clinical teaching models with fewer total hours of simulated teaching. ${ }^{[7]}$

\subsubsection{Conceptual framework: Educational practices do- mains for effective high-fidelity clinical simulation in nursing education}

Current evidence suggests that key learning outcomes associated with competent clinical nursing practice such as self-confidence, mastery of clinical skills and critical thinking abilities, are achieved when high fidelity simulation is woven throughout the curriculum. ${ }^{[5]}$ Parker and colleagues found that simulation is most effective when individual patient scenarios are designed to integrate both nursing theory and clinical skills, and progress in complexity over time. ${ }^{[23]}$ Similarly, Katz and colleagues' review of the integration of baccalaureate nursing programs and simulation throughout the core nursing curriculum revealed student mastery of clinical skills and professional practice competencies are enhanced. ${ }^{[24]}$

To improve the overall effectiveness of simulation in nursing education, Jeffries ${ }^{[12]}$ describes four educational practice domains necessary for designing and implementing high quality simulation sessions. The educational practice domains associated with effective problem-based teaching set forth by Jeffries include: active learning, collaboration, diverse ways 
of learning, and high expectations. ${ }^{[12]}$ The extent to which nurse educators integrate these best practices in the design and delivery of clinical simulation sessions, the higher the quality of the student learning experience.

The first component of Jeffries' model is active learning. Active learning, including direct performance feedback, is integral to the clinical simulation experience. ${ }^{[25]}$ It is expected that new nurses possess the ability to be self-directed and engage in clinical situations, and can be facilitated by simulation.

The balance between participation and feedback is determined in the design of the simulation experience. Instructional strategies associated with active-learning stress the importance of allowing students to work through an evolving clinical situation by gathering and analyzing data to determine an appropriate course of action to resolve patient problems. ${ }^{\left[{ }^{8-11]}\right.}$ The process of learning-by-doing inherent in the active-learning domain enables students to experiment, develop critical thinking skills, and reflect on their overall performance prior to receiving feedback from their peers and clinical instructor.

The second component of Jeffries' best practice model is collaboration. Howard and colleagues ${ }^{[26]}$ suggest that learning is enhanced when it represents a team effort through collaboration rather than independent learning. Parker and colleagues $^{[23]}$ identified students' perception of collaboration, peer solidarity, faculty support and guidance and selfconfidence as significantly higher in simulation teaching as compared to the traditional hospital clinical teaching. More broadly, effective collaboration among nurses and other health professionals is fundamental to providing high-quality, well-coordinated patient care. ${ }^{[1,8]}$ Well-designed simulation scenarios emphasizing collaboration plays an important role in developing new nurses' skills to establish meaningful and productive professional relationships with clients, families, and colleagues. ${ }^{[23,26]}$

The third aspect of Jeffries's best practice model is diverse ways of learning. Given their varying social and cultural backgrounds, students have different learning styles and expectations. High-fidelity simulation provides a controlled environment appropriate to these diverse learning styles. ${ }^{[8,9]}$ High fidelity simulation enables instructors to facilitate students' different learning styles because simulation requires students to use all of their senses to work through a clinical scenario. In turn, the active learning process that is the hallmark of simulation enables students to internalize what they have experienced. ${ }^{[27]}$ Examples include a variety of learning cues in the form of the physical set up of the simulation room, the oral report, the physical exam with realistic sounds, and practicing clinical skills such as wound care or donning personal protective equipment.

Finally, although the role of high expectations is rarely addressed in the literature, Jeffries and Rizzolo ${ }^{[12]}$ suggest that high standards are necessary for students to achieve favorable outcomes through simulation. Clear objectives and goals should be provided as well as support and assistance so students can achieve mastery of skills and knowledge during the simulated activity. In addition, when faculty set high performance expectations, students' perceptions of the realism of simulation and expectations for collaborative learning and team building improve. ${ }^{[3,8,11]}$

\subsubsection{NYU meyers clinical teaching model}

In 2006, the NYU Meyers College of Nursing developed an innovative clinical teaching model in which $50 \%$ of the clinical hours in the four core medical-surgical courses in the undergraduate program were replaced with high-fidelity human mannequin simulation. ${ }^{[3]}$ Recognizing the advantages and limitations of both simulation and traditional clinical teaching approaches, faculty adopted the high-dose clinical simulation teaching model. At the outset of a curricular redesign initiative, faculty agreed that the realism of welldesigned clinical scenarios using high-fidelity simulation was an equally valuable learning experience to the traditional hospital-based clinical teaching model. Simulation sessions are guided by Jeffries' educational practices model to emphasize the principles of active learning, collaboration, diverse ways of learning, and high expectations. ${ }^{[2,11,28]}$

Clinical simulation enabled the faculty to exert greater control over the range of patient problems and exposure to specific clinical skills that students experienced across the four core-medical surgical courses in the undergraduate program. In turn, the focus of the traditional hospital based clinical teaching shifted to emphasize learning opportunities to develop students' skills in therapeutic communication, care planning and goal setting, interprofessional collaboration and reflective practice. ${ }^{[2,11,28]}$

To reinforce the value that faculty placed on each clinical teaching approach, the simulation sessions are referred to as 'on-campus' clinical and the hospital based clinical sessions are referred to as 'off-campus' clinical. The faculty member teaching the didactic course serves as the course leader responsible for coordinating the work of the clinical faculty responsible for teaching the students in the on-campus and off-campus clinical sessions to ensure continuity across the teaching team. Students are required to follow the same dress code and preparation policies for both clinical learning experiences. ${ }^{[2,29-31]}$ 
We integrated high-fidelity human mannequin simulation into the undergraduate program curriculum in the following ways. First, we created learning objectives and course outlines for the four core didactic medical surgical courses. The content presented in each course was leveled to take students' experience and mastery with the underlying nursing practice principles into account. For example, the medical-surgical course in the first semester emphasizes the basic principles of the nursing process, physical assessment and data gathering skills. In comparison, the fourth semester medical surgical course requires students to gather and analyze more complex physical assessment data, medical and nursing orders, as well as taking medications and their side effects into account, to develop an appropriate nursing care plan. Next, the learning objectives for each on-campus and off-campus clinical session were aligned with the weekly topics taught in the didactic course. Clinical topics covered in the weekly lecture course are reinforced and elaborated in the on-campus and off-campus clinical sessions. ${ }^{[2,29-31]}$

To support the alignment of the course content across the four core didactic and clinical classes, the faculty developed a portfolio of patient scenarios for each on-campus clinical simulation session. The original case scenarios were purchased from Laredal, the simulator manufacturer, and revised by faculty to reflect local population demographics and clinical practice patterns. Supplemental materials for instructors and students, including national clinical practice guidelines, discussion questions and rationales for the most appropriate nursing interventions, were also developed.

Finally, we created orientation programs with the goal of preparing both the clinical faculty and the students with the skills to gain the full benefits of the high-fidelity human mannequin simulation in the clinical teaching model. The faculty orientation program focused on developing skills in both problem-based teaching and mastery of the technology required to animate the human mannequin simulators and create a realistic hospital environment for the students during the on-campus clinical simulation sessions. Similarly, the student orientation program emphasizes the goals of clinical simulation within the broader clinical teaching model and set forth the expectations for class preparation and participation in the simulation sessions.

\section{METHOD}

\subsection{Design}

The data presented here were collected as part of a program evaluation study at the NYU Meyers College of Nursing examining the effects of the simulation clinical teaching model described above on expanding faculty capacity. ${ }^{[3,29]}$ The study was conducted by an independent evaluation team not affiliated with the College of Nursing. All study procedures were approved by the Institutional Review Board at New York University.

\subsection{Setting}

Students were surveyed at two time points within the twoyear (four semester) baccalaureate curriculum. We collected data from the student nurses using the Educational Practices Questionnaire (EPQ) at the middle of their-program (at the end of the second semester), and at the end of their program. A total of 168 students completed data collection at both time points and thus could be compared over time.

\subsection{Instruments}

The EPQ is a 16-item validated measure that assesses aspects of simulation-based learning, and includes the four domains of active learning; collaboration; diverse ways of learning; and high expectations. ${ }^{[6,28]}$ In 2003, the NLN/Laerdal simulation research study developed the EPQ instrument. ${ }^{[31]}$ The EPQ has been shown to have good reliability, with Cronbach alphas ranging from .88 to .93 across the four domains ${ }^{[30]}$ for both the presence of features in simulation and .91 for the importance of these features. ${ }^{[28]}$ For each statement, students were asked two separate questions. First, they were asked to indicate how much they agreed or disagreed with statements reflecting exposure to the domain (e.g., for the active learning domain, they were asked the degree to which they agreed with the statement, "I received cues during the simulation in a timely manner."), and then to rate how important each item was in supporting their individual learning. Students rated their answers on a five-point Likert scale ranging from "strongly disagree" to "strongly agree" for the exposure items, and from "not at all important" to "very important" for the important items.

\subsection{Procedure}

The purpose of the study was explained orally to the students by the independent evaluator after the professor had left the classroom. Paper copies of the survey were then handed out to the students. Participation was voluntary and students who did not wish to participate were free to leave or simply not complete the survey. A written informed consent was included as the cover sheet of the survey, and students were asked to voluntarily put their names on the survey to enable us to track their perceptions over time. Surveys took approximately 15-20 minutes to complete.

\subsection{Measures and data analyses}

Names were converted to identification numbers and matched across time points. Data from surveys were entered directly into SPSS (v. 21.0; IBM Corporation) for analysis. Domain 
scores for the EPQ were calculated by summing responses to all items in the domain; higher scores represent student's assessment of the use of best practices embedded in the simulation sessions and the importance assigned to each educational practice in the simulation sessions. There were eight items in the Active Learning Domain and two items in each of the other three domains. To make the domain scores comparable, the Active Learning Domain score was divided by five, while all other domain scores were the sum of the two items specific to each domain. Paired $t$-tests were used to assess changes in student EPQ scores between mid- and end-program data collection points.

\section{Results}

\subsection{Participants}

A total of 385 students completed the EPQ at the midprogram assessment and 341 completed the EPQ at the endprogram assessment. We analyzed data from the 168 students who completed the EPQ at both assessment points. There were no statistically significant differences in demographic characteristics between students who completed the EPQ at both time points and those who did not.

Table 1 shows demographic data from the 169 participants at the mid-program assessment. As shown in Table 1, participants were, on average, 26.12 years of age (range 20-50) and $87.5 \%$ were female. Most $(86.5 \%)$ identified as non-Latino/a, and either Caucasian/White $(61.6 \%)$ or Asian/Pacific Islander $(24.4 \%)$. Most $(82.0 \%)$ were in the accelerated degree program, which offers a bachelor's degree in fifteen months by including summer classes.

\subsection{EPQ domain scores at mid- and end-point program assessments}

Table 2 shows results from paired $t$-tests. These results show significant increases on scores in two of the EPQ domains and one of the EPQ importance domains. Student scores increased significantly on the items in the Active Learning and High Expectations domains, and on the importance items in the Collaboration domain.

Table 1. Demographic characteristics of the participating students

\begin{tabular}{|c|c|c|}
\hline \multicolumn{3}{|l|}{$N=168$ respondents } \\
\hline Variable & $\mathbf{N}$ & $\%$ \\
\hline \multicolumn{3}{|l|}{ Gender } \\
\hline Male & 21 & $12.5 \%$ \\
\hline \multirow[t]{2}{*}{ Female } & 147 & $87.5 \%$ \\
\hline & Mean & Range \\
\hline Age & 26.12 & $20-50$ \\
\hline Ethnicity & $\mathbf{N}$ & $\%$ \\
\hline Latino/a & 12 & $7.4 \%$ \\
\hline Non-Latino/a & 141 & $86.5 \%$ \\
\hline Prefer Not to Identify & 10 & $6.1 \%$ \\
\hline \multicolumn{3}{|l|}{ Race } \\
\hline African-American/Black & 13 & $7.9 \%$ \\
\hline Asian/Pacific Islander & 40 & $24.4 \%$ \\
\hline Caucasian/White & 101 & $61.6 \%$ \\
\hline Native American/Alaskan Native & 2 & $1.2 \%$ \\
\hline Other & 10 & $6.1 \%$ \\
\hline Prefer Not to Identify & 6 & $3.7 \%$ \\
\hline \multicolumn{3}{|l|}{ Program } \\
\hline Traditional & 30 & $18.0 \%$ \\
\hline Accelerated & 137 & $82.0 \%$ \\
\hline
\end{tabular}

* Note. Inconsistent sample sizes reflect missing data on individual items.

Table 2. EPQ domain scores at mid- and end-program assessments

\begin{tabular}{lllll}
\hline Domain & Mid & End & Sig. ( $\boldsymbol{p}$ value) & CI \\
\hline Exposure Domains & & & & .027 \\
Active Learning & 7.89 & 8.18 & $\mathrm{~ns}$ & $0.03-0.56$ \\
Collaboration & 9.09 & 9.13 & $\mathrm{~ns}$ & $-0.20-0.28$ \\
Diverse Ways of Learning & 7.30 & 7.41 & .004 & $-0.24-0.46$ \\
High Expectations & 7.82 & 8.29 & & $0.15-0.79$ \\
Importance Domains & & & $\mathrm{ns}$ & $-0.10-0.36$ \\
Active Learning & 8.36 & 8.49 & .021 & $0.06-0.69$ \\
Collaboration & 8.35 & 8.72 & $\mathrm{~ns}$ & $-0.39-0.17$ \\
Diverse Ways of Learning & 8.54 & 8.43 & $\mathrm{~ns}$ & $-0.32-0.27$ \\
High Expectations & 8.62 & 8.60 & & \\
\hline
\end{tabular}

\section{Discussion}

We examined, using the reliable EPQ instrument, students' perceptions of the presence of educational best practices and the importance that students assigned to each domain to support learning in an innovative clinical teaching model that substitutes $50 \%$ of the clinical practice hours with highfidelity simulation. In this model, that substitutes $50 \%$ of the clinical practice hours with high-fidelity simulation, faculty 
view well-designed high-fidelity simulation sessions as an equally valuable learning experience as traditional hospitalbased clinical teaching.

Scores were generally high on all domains, suggesting that students recognize and value the role that high-fidelity simulation plays in their learning experience. As students progressed through the four semester curriculum, they increasingly agree that they have been exposed to active learning paired with high expectations of their performance. Although no changes were seen in reported exposure to diverse ways of learning or collaboration, this may have been due to the fact that scores were generally high on items in each of these domains, leaving little room for improvement. ${ }^{[29,30]}$

Students' ratings also showed an increase in the degree to which they believed collaboration was important. This finding may reflect a key advantage of clinical simulation, namely that students have frequent hands-on learning experiences, requiring that they work with other student nurses and often with members of other disciplines (via interactions that are built into the simulation scenarios). It is likely that highfidelity simulation provides a greater amount of hands-on experience because this experience is programmed into each simulation session, in contrast to the potentially-limited clinical exposure these students may receive in a traditional clinical setting.

\section{Limitations}

The limitations of this study should be considered when interpreting the results. First, it is important to note that the number of clinical teaching hours spent in in-person or simulated learning activities is not regulated by our State Board of Nursing and the Department of Education. Thus, the market and the regulatory environment were conducive for adopting a high-dose simulation model. Other schools of nursing may not face the same market demands, and thus, a high-dose simulation model may not be a feasible or appropriate. Nonetheless, a foundation of nursing practice is the cultivation of clinical reasoning skills and thus use of this problem-based teaching approach is a viable alternative for clinical experiences.

Second, we demonstrate that the Educational Practices Questionnaire (EPQ) is a useful instrument for gathering data on student's perceptions on the design and usefulness of simulation as a component of a robust clinical teaching model ${ }^{[13]}$ Nurse educators and researchers can use the EPQ to inform program improvement initiatives to promote the use of evidence-based simulation teaching in higher nursing education settings.

Next, the relatively small number of students whose assessments could be matched across time periods is a second Published by Sciedu Press limitation of this study. In designing the overall study, we elected to allow students to decide whether to identify themselves on their surveys. These surveys were administered in classroom settings, and many students may have therefore been reluctant to provide their names, even though surveys were administered by an evaluator not affiliated with the program. Nonetheless, our study is one of the few employing a longitudinal design to assess changes in students' perceptions of effective curricular design to support problem-based learning in a simulation clinical teaching model. ${ }^{[29,30]}$

Finally, the study findings are not generalizable to all nursing students; $80 \%$ of the undergraduate students in this study were enrolled in the accelerated, second-degree program. According to the American Association of the Colleges of Nursing (AACN), at the time we conducted this study, there were 233 accelerated BS programs with approximately 13,605 enrolled students. ${ }^{[2]}$ Our program is part of a larger trend in nursing education focused on increasing the supply of registered nurses in a timely and efficient manner. The students in the accelerated and traditional bachelor's degree programs are in the same classroom, and as our results show, there were no significant differences in perceptions of the presence or importance of educational practices known to promote effective problem-based learning between the two groups of students, thus improving our confidence in the results.

\section{Conclusion}

This study contributes to the literature on the efficacy of simulation teaching models in undergraduate nursing education. We show that students' perceptions of their exposure to the active learning and high expectations domains, which are associated with effective problem-based teaching, increased over time. Additionally, students valued the collaboration required to work through the patient care scenario presented every other week in the weekly clinical simulation sessions. We add to the growing body of research that examines the effectiveness of different clinical teaching approaches that promote problem-based teaching and students' ability to enact their roles as professional registered nurses.

\section{ACKNOWLEDGeMENTS}

Supported in part by a grant from the Robert Wood Johnson Foundation's Evaluating Innovations in Nursing Education Program Grant \#68172. H. Richardson, DrPH, RN, FAAN, Principal Investigator. L. Goldsamt, PhD and J. Simmons, EdD, National Development and Research Institutes, Inc., Program Evaluators.

\section{CONFlicts of InTEREST Disclosure}

The authors declare that there is no conflict of interest, financial or otherwise. 


\section{REFERENCES}

[1] Mennenga HA, Smyer T. A model for easily incorporating teambased learning into nursing education. International Journal of Nursing Education Scholarship. 2010; 7(4): 14. https ://doi .org/10 .2202/1548-923x.1924

[2] Stroup C. Simulation usage in nursing fundamentals: Integrative Literature Review. Clinical Simulation in Nursing. 2014; 10(3): e155e164. http://dx.doi.org/10.1016/j.ecns.2013.10.004

[3] Richardson H, Goldsamt LA, Simmons J, et al. Increasing faculty capacity. Nursing Education Perspectives. 2014; 35(5): 308-314. https://doi.org/10.5480/14-1384

[4] Spector N. Systematic review of nursing education outcomes: An evolving review. NCSBN, 2006 April; Chicago, IL. Available from: https://www.ncsbn.org/Final_Sys_Review_04_06.pdf

[5] Cant RP, Cooper SJ. Use of simulation-based learning in undergraduate nurse education: An umbrella systematic review. Nurse Education Today. 2017; 49: 63-71. PMid:27902949 http://dx.doi .org/10. 1016/j.nedt. 2016.11.015

[6] Tosterud R, Hedelin B, Hall-Lord ML. Nursing students' perceptions of high- and low-fidelity simulation used as learning methods Nurse Education in Practice. 2013; 13(4): 262-270. PMid:23454066 http://dx.doi.org/10.1016/j.nepr.2013.02.002

[7] American Association of Colleges of Nursing. New AACN Data Confirm Enrollment Surge in Schools of Nursing Washington, D.C.: American Association of Colleges of Nursing: 2015. Available from: http://www.aacn.nche.edu/news/articles/20 15/enrollment

[8] Alfes CM. Evaluating the use of Simulation with beginning nursing students. Journal of Nursing Education. 2011; 50(2): 89-93. https://doi.org/10.3928/01484834-20101230-03

[9] Howard VM, Englert N, Kameg K, et al. Integration of simulation across the undergraduate curriculum: student and faculty perspectives. Clinical Simulation in Nursing. 2011; 7(1): e1-e10. http://dx.doi.org/10.1016/j.ecns.2009.10.004

[10] Schoening AM, Sittner BJ, Todd MJ. Simulated clinical experience: Nursing students' perceptions and the educators' role. Nurse Educator. 2006; 31(6): 253-258. PMid:17108788 https : //doi .org/10 .1097/00006223-200611000-00008

[11] Yuan HB, Williams BA, Fang JB. The contribution of high fidelity simulation to nursing student's confidence and competence: A systematic review. International Nursing Review. 2012; 59(1): 26-33. http://dx.doi.org/10.1111/j.1466-7657.2011.00964.x

[12] Jeffries PR, Rogers KJ. Simulation in Nursing Education: from Conceptualization to Evaluation. 2005; 21-33. New York: National League for Nursing. New York.

[13] Franklin AE, Burns P, Lee CS. Psychometric testing on the NLN Student Satisfaction and Self-Confidence in Learning, Simulation Design Scale, and Educational Practices Questionnaire using a sample of pre-licensure novice nurses. Nurse Education Today. 2014; 34(10): 1298-1304. PMid:25066650 http://dx.doi.org/10.10 16/j.nedt. 2014.06.011

[14] Hayden JK, Jeffries PJ, Kardong-Edgren S, et al. The National Simulation Study: Evaluating simulated clinical experiences in nursing education. Unpublished research protocol, Chicago, IL: 2011. National Council of State Boards of Nursing.

[15] Meakim C, Boese T, Decker S, et al. Standards of Best Practice: Simulation Standard I: Terminology. Clinical Simulation in Nursing. 2013; 9(6S): S3-S11. http://dx . doi .org/10.1016/j . ecns . 20 13.04 .001
[16] Chickering AW, Gamson ZF. Seven principles for good practice in undergraduate education. American Association for Higher Education Bulletin. 1987; 39(7): 3-7.

[17] Cook DA, Hatala R, Brydges R, et al. Technology-enhanced simulation for health professions education: A systematic review and metaanalysis. JAMA: Journal of the American Medical Association. 2011; 306(9): 978-988. https://doi.org/10.1001/jama. 2011.1234

[18] Kardong-Edgren S, Willhaus J, Bennett D, et al. Results of the National Council of State Boards of Nursing National Simulation Survey: Part II. Clinical Simulation in Nursing. 2012; 8(4): e117-e123. http://dx.doi.org/10.1016/j.ecns. 2012.01.003

[19] Norman J. Systematic review of the literature on simulation in nursing education. ABNF Journal. 2012; 23(2): 24-28. PMid:22774355

[20] Shinnick MA, Woo M, Mentes JC. Human patient simulation: State of the science in prelicensure nursing education. Journal of Nursing Education. 2011; 50(2): 65-72. PMid:21210612 https: //doi.org/10.3928/01484834-20101230-01

[21] National Council of State Boards of Nursing. NCSBN releases results of National Simulation Study. 2014; Available from: https: //www.ncsbn.org/685.htm

[22] Kong LN, Qin B, Zhou YQ, et al. The effectiveness of problembased learning on development of nursing students' critical thinking: A systematic review and meta-analysis. International Journal of Nursing Studies. 2014; 51(3): 458-469. PMid:23850065 http://dx.doi.org/10.1016/j.ijnurstu.2013.06.009

[23] Parker RA, McNeill J, Howard J. Comparing pediatric simulation and traditional clinical experience: Student perceptions, learning outcomes, and lessons for faculty. Clinical Simulation in Nursing. 2015; 11(3): 188-193. http://dx.doi.org/10.1016/j.ecns. 2015.0 1.002

[24] Katz GB, Pfeifer KL, Armstrong G. Assessment of patient simulation use in selected baccalaureate nursing programs in the United States. Simulation in Healthcare. 2010; 5(1): 46-51. PMid:20383091 https ://doi.org/10.1097/SIH.0b013e3181ba1f46

[25] Jeffries PR. Simulation in Nursing Education: From Conceptualization to Evaluation. 2007; New York: National League for Nursing.

[26] Reese CE, Jeffries PR, Engum SA. Learning together: Using simulations to develop nursing and medical student collaboration. Nursing Education Perspectives. 2010; 31(1): 33-37. PMid:20397478

[27] Hallmark BF, Thomas CM, Gantt L. The educational practices construct of the NLN/Jeffries simulation framework: State of the science. Clinical Simulation in Nursing. 2014; 10(7): 345-352. http://dx.doi.org/10.1016/j.ecns.2013.04.006

[28] Jeffries PR, Rizzolo M. NLN-Laerdal project summary report, designing and implementing models for the innovative use of simulation to teach nursing care of ill adults and children: a national multi-site study. 2006. New York: National League for Nursing.

[29] Richardson H, Gilmartin MJ, Fulmer T. Shifting the clinical teaching paradigm in undergraduate nursing education to address the nursing faculty shortage. Journal of Nursing Education. 2012; 51(4): 226-231. http://dx.doi.org/10.3928/01484834-20120210-04

[30] Goldsamt L, Simmons J. Final Report to National Program Office Evaluating Innovations in Nursing Education Program. New York University College of Nursing. 2012; Grant Number 68172.

[31] Kardong-Edgren S, Adamson K, Fitzgerald C. A review of currently published evaluation instruments for Human Patient Simulation. Clinical Simulation in Nursing. 2009; 6(1): e25-e35. https: //doi.org/10.1016/j.ecns.2009.08.004 